\title{
Economic Security of the Region's Periphery in Conditions of Digitalization, Urbanization and COVID-19
}

\author{
E.B. Dvoryadkina, K.M. Guseynly*, and A.A. Sobyanin \\ Ural State University of Economics, 620144 Ekaterinburg, Russia
}

\begin{abstract}
The study deals with three factors of general nature and their impact on the economic security of the region's periphery. The essence of regional periphery economic security is described. Processes such as digitalization, urbanization and COVID-19 are considered and their impact on the economic security of the region's periphery is described. These factors are considered separately, and the characteristics of positive and negative effects coming from them are presented. The relationship between all three factors is revealed, and the influence of these processes in the aggregate is described. It was found that, cumulatively, the effect of digitalization, urbanization and COVID-19 on the economic security of the region's periphery is changing and may acquire a completely different nature than the impact of factors individually.
\end{abstract}

\section{Introduction}

Around the world, many different processes are running simultaneously, which are often considered separately, despite the fact that they have an impact on the economy of various economic entities and entire states in an integrated manner. In this case, the processes can lead to both positive and negative effects. Negative phenomena play a major role in the analysis, as they require greater efforts to minimize the damage they cause. It is the minimization of damage from possible or occurring threats that is part of the subject area of economic security. Economic security can be considered at different levels, from the personal to the global or national level. However, considering the economic security of a state as a whole often leads to inaccurate conclusions due to blurring of information, especially if we consider the largest country in the territory as Russia. Therefore, it is worthwhile to go down to the hierarchical level lower depending on the level of the region; however, there will also be differences in the levels of municipal development (Municipality). Therefore, for more accurate detection of threats it is worth considering the economic security of the municipality, but in Russia there are quite a few of them. For example, the Sverdlovsk Region has 94 municipalities, which raises the question of their grouping in order to reflect their specifics. In the framework of this research it is proposed to consider the region from the point of view of "center-periphery" theory, namely

${ }^{*}$ Corresponding author: guseinli_kamal@mail.ru 
peripheral territories of the region, which will be similar in their specifics and scale in economic activity of the region. The impact of global processes will differ depending on the territory.

The world is now facing COVID-19, which is not only slowing down economic processes but also stopping them, resulting in invaluable damage to the economy. This pandemic is a major factor that affects economic security at all levels. However, we should not forget about other processes that are currently underway and also have an impact on development. Such processes include the digitalization of the economy, which is the transition to virtual space and the emergence of new processes. From the point of view of economic security, the process of urbanization is also interesting, by which this study understands the process of population migration to major cities from rural areas in order to improve their quality of life. Thus, we see that there is more than one process that needs to be studied and anticipated for possible threats. At the same time, these processes, proceeding simultaneously, influence each other, which leads to the possibility of new threats emerging.

\section{Materials and Methods}

When considering the economic security of the region's periphery, it is necessary to understand what the periphery of the region is. If we consider a region as a constituent entity of the Russian Federation, it consists of municipality formations and it is in essence an economic space. A.G. Granberg writes: "Economic space is a saturated territory that contains many objects and connections between them: settlements, industrial enterprises, economically developed and recreational areas, transport and engineering networks, etc."[1]. In other words, the region is a territory where different economic agents interact. The economic area can be conditionally divided into center and periphery, which will be certain levels of its hierarchy. According to J. Fridman, the peripheral territory is "a set of remote and underdeveloped territories with slow modernization serving as a source of resources and consumer of innovations" [2]. According to this fact, the center will be a developed system, more innovative than the periphery, and the periphery will be a source of resources to serve the center. Thus, the region, as an economic area, can be divided into center and periphery. This division allows grouping individual municipalities and highlighting certain specific features [3]. In the case of the periphery, this area will be described as an underdeveloped area where the innovation component has not been developed and, consequently, the area will be a consumer of innovations coming from the center, as well as the migration of population to the center due to the fact that the population in this case is represented as a labor force that will be attracted by the center.

The next step is to define what economic security (ES) of the periphery of the region is. There are many different definitions of economic security, but they are usually linked to a certain level (national, regional, municipal). From this point, the definition given by Petrov I.V. and Oganyan T.M., in their opinion, the economic security of the territory - "the ability of the territory to withstand external and internal threats" is interesting [4]. In this case, there is no link to a certain level of power, and we are talking about the whole territory. However, due to the fact that the periphery has its own characteristics, it is necessary to take them into account. It should also be noted that many authors identify the goal of economic security of any level in the definition, which is to ensure stable development of the system. For example, according to N. Sorokina, "...From the point of view of a dynamic approach, achieving economic security of regions should be considered as a result of their sustainable development"[5]. Thus, the economic security of a region's periphery is a system that is stable to external and internal negative factors, a stably developing system, the key component of which is a balance of interests of the center and periphery of the 
region. In this case, the focus should be on the balance of interests, because the periphery, by supplying resources to the center, must meet its own need for innovation.

As we can see, the economic security of a region's periphery must be resistant to negative factors, which requires identifying these factors as well as understanding the processes they cause. Several major factors can be identified that are characteristic of the entire global community and apply to all lower levels. These factors include: digitalization, urbanization, COVID-19 pandemic.

\section{Results and Discussion}

The digitalization of the economy is a global trend, which implies the transfer of information into the digital environment, which ultimately leads to increased economic efficiency and improved quality of life [6]. When considering digitalization as a factor, it is necessary to understand that the result of this trend is the digital economy, which can be understood as "economic activity in which the key factor of production is data in digital form, processing of large volumes and the use of the results of analysis of which compared to traditional forms of management can significantly improve the efficiency of various types of production, technology, equipment, storage, sale, delivery of goods and services" [7]. In this case, we are talking about the fact that human activity is partially moving into the digital world, where one can receive education, purchase various goods and services, carry out labor activities and much more. Speaking about the impact of digitalization on the economic security of the periphery of the region, we note that it is in the center of the region, due to its innovativeness, that digitalization processes will take place in the first place. In other words, the periphery will get a certain result from the center within a relationship. This fact can be explained by the fact that it is in the center that highly qualified personnel are concentrated, as well as by the fact that the scientific base of the region is concentrated in the center and there is a stronger infrastructure potential compared to the periphery. As for the positive impact of digitalization on the economic security of the periphery, we can distinguish the following: due to the emergence of distance education, the population of the periphery has the opportunity to receive education without leaving their homes, etc. In other words, due to the development of digitalization, the population's access to various services is improving, however, due to the time lag, an uneven improvement in the quality of life can be observed, which leads to an increase in social inequality between the center and the periphery, which is a threat to the periphery. As for the positive impact of digitalization, we note that companies have some positive aspects, such as cost reduction, increased productivity, acceleration of business processes, etc. can be observed. If we talk about threats, they include: digital fraud, job cuts due to process automation, information security issues become important. Thus, digitalization has a significant impact on the development of the entire territory, but the most important element for the periphery will be the fact that digitalization will lead to an improvement in the quality of life of the population in the area, which may subsequently lead to a reduction in losses of their own labor force through increased attractiveness. In this context, the process of increasing the connectivity of the region's economic area comes to the fore.

In the following we will briefly consider the process of urbanization. Urbanization can be defined as a significant increase in the role of cities in the socio-economic development of society [8]. This study, as was noted, shows that population is moving from rural to urban areas. At the same time, we can say that the population migrates to the largest cities in the regions. In other words, the population migrates from the periphery of the region to the center (this process may include intermediate points, because there are also cities in the periphery that attract the population, but later from these cities the population also migrates to larger cities, and eventually to the center). There are many reasons for migration, but it 
will all come down to the fact that the center is a more attractive area for living due to the quality of life there. From the point of economic security of the periphery of the region, this process causes a number of threats, including reduction of population, lack of highly qualified personnel, decline in living standards in the periphery against the background of the center's development, etc. Thus, the process of urbanization, on the one hand, has a positive impact on the level of development of the center and, on the other hand, leads to threats to the economic security of the periphery of the region. These threats can be seen in the example of the Sverdlovsk region, which is home to Ekaterinburg's urban agglomeration, where about $46 \%$ of the region's total population lives on $7 \%$ of the territory. At the same time, there is a migratory outflow of just over 3.5 thousand people from the periphery, with migration growth in the center of the region. If we talk about the total number of workers, we will see a $0.4 \%$ decrease in 2019 compared to 2018 in the periphery. As for the quality of life, we can only point out that the salary level in the periphery is $28 \%$ lower than in the center. Urbanization has a strong impact on the region's peripheral ES, which is the emergence of additional threats. Next, let's examine the COVID-19 pandemic. The pandemic has affected the whole world and has a significant impact on the economies of all countries [9]. In terms of how devastating its impact is, it is almost impossible to predict the exact impact of the pandemic at this time. Many companies have had to physically shut down their operations, but now they are operating with many different constraints and fears that production processes may eventually be shut down again. If we talk about who eventually suffers from the pandemic, then in this case we can already give an unequivocal answer, that is everything. Companies forced to stop or limit their activities or have suffered colossal losses of profit, and it should be remembered that companies are forced to comply with additional requirements entailing additional costs. The government needs to have a positive impact on the situation, which leads to additional expenditures in the budgets of all levels, while the level of tax payments will be lower than expected, and these are additional threats. In terms of population, we can observe a decline in quality of life caused not only by the pandemic itself due to high morbidity rates, but also due to the fact that companies are reducing their staff, thus increasing unemployment. Due to the optimization of expenditures, many enterprises have seen a reduction in wages and income levels. Thus, we can see that the impact of the pandemic is spreading to everyone. At the same time the whole territory suffers regardless of its status and level. As for the number of infected people, it should be noted that $71 \%$ of those infected fall in the center of the region against $29 \%$ in the periphery (in the Sverdlovsk Region), in other words, because the population density in the periphery is lower than in the center, it is less susceptible to infection. However, on the other hand, the periphery is worse developed, because the main medical facilities are concentrated in the center.

These factors independently influence the economic security of peripheral territories of the region. COVID-19 and urbanization are increasing the number of threats and hampering development processes, and in some cases they are reversing development at all. Digitalization on the one hand is a potential opportunity for development, and on the other hand carries certain threats. However, these factors, despite the fact that they act independently, also have an impact on each other. In interaction with each other, they can increase their impact. Digitalization, due to its impact on living standards, can slow down urbanization and minimize threats to the periphery. This result is achieved by improving the quality of life of people in the periphery. Thus, due to the fact that education can be obtained remotely, there is no need to move to the center, the same situation with the ability to work remotely, etc. If we talk about the relationship between urbanization and COVID19 , in this case due to urbanization processes the population density in the center increases, which contributes to the spread of infection and leads to even stronger negative consequences. At the same time, we see that due to the low density in the periphery, the 
pandemic is less affected. If we talk about the relationship between COVID-19 and digitalization, we can argue that the pandemic is an impetus for the development and acceleration of digitalization processes. Despite all the negative consequences, it is precisely because of the pandemic that one has to switch to new types of jobs (previously, remote work was a rarity, but now it is becoming the norm), while new directions in the field of digitalization are developing, new needs are emerging. It is thanks to the pandemic that previously less common processes had to be promoted (e.g. distance learning used to be quite underdeveloped, and because of the pandemic all educational organizations had to find and switch to it). One of the inhibiting factors for digitalization is the population's uncertainty about such technologies, but because of the pandemic, people have to deal with different digitalization processes and thus get used to them and realize that this is the norm. At the same time, the push is not only for the center, but also for the periphery, which is forced to catch up with the center in this respect, thus making it more attractive to attract people. Thus, we can say that the pandemic has given a certain impetus to the development of digitalization, which in turn increases the attractiveness of the periphery of the region, and as a result, leads to slower urbanization processes.

\section{Conclusion}

The economic security of the region's periphery is influenced by many factors. Currently, three important factors can be identified as having a significant impact, in particular: digitalization, urbanization and the COVID-19 pandemic. When we consider the impact of these factors on the economic security of the region's periphery, we can say that digitalization has mainly positive effects, while urbanization and COVID-19 mainly have negative effects and create certain threats to the economic security of the region's periphery. If we talk about these factors as an aggregate, we can say that they influence each other and the effect on economic security changes. Thus, considering the factors as a whole, we can say that the COVID-19 pandemic leads to a positive impulse for the development of digitalization, which eventually leads to the reduction of migration processes from the periphery of the region, thus strengthening the economic security of the periphery of the region. Thus, a comprehensive approach to analysis can also highlight the positive aspects of seemingly negative processes.

\section{References}

1. A.G. Granberg, Fundamentals of regional economics, textbook for universities (2000)

2. J. Friedman, Regional development policy: A Case Study of Venezuela (1966)

3. E.I. Kaibicheva, Development of peripheral urban areas in the economic space of the region (on the example of the Sverdlovsk region) (2016)

4. I.V. Petrov, T.M. Ohanyan, Space of the economy, 1-3, 201 (2012)

5. N.Yu. Sorokina, Bulletin of the Plekhanov Russian University of Economics, 5 (2017)

6. V. Khalin, G. Chernov, Management Consulting, 10 (2018)

7. Decree of the President of the Russian Federation of May 9, 2017 No. 203 "On the Strategy for the Development of the Information Society in the Russian Federation for 2017 - 2030"

8. O.Yu. Aseeva, News of the South-Western State University, 4(21) (2016)

9. M.N. Dudin, N.V. Lyasnikov, Social studies. Art. Sociology. Culture, 2(79) (2020) 